\title{
Predictors of Burnout in Public Library Employees
}

Michelle P. Salyers

Professor, Department of Psychology, Indiana University Purdue University Indianapolis (IUPUI); Director, ACT Center of Indiana

\author{
Melanie A. Watkins \\ Doctoral Student in Clinical Psychology, Department of Psychology, IUPUI
}

Amber Painter

Southwest Regional Coordinator, Professional Development Office, Indiana State Library

Eric A. Snajdr

Associate Librarian, University Library, IUPUI

Lauren O. Gilmer

Graduate Student in Industrial/Organizational Psychology, Department of Psychology, IUPUI

Jennifer M. Garabrant

Program Manager, ACT Center of Indiana, Department of Psychology, Indiana University Purdue University Indianapolis (IUPUI)

Nancy H. Henry

Project Manager, ACT Center of Indiana, Department of Psychology, Indiana University Purdue University Indianapolis (IUPUI)

Address correspondence to:

Michelle P. Salyers, Ph.D.

Department of Psychology, LD 124

402 N. Blackford St.

Indianapolis, IN 46202

Tel: (317) 274-2904; Fax: (317) 274-6756; Email: mpsalyer@iupui.edu

Acknowledgements and Disclosures: The authors report no conflicts of interest.

This is the author's manuscript of the article published in final edited form as:

Salyers, Michelle \& A. Watkins, Melanie \& Painter, Amber \& A. Snajdr, Eric \& O. Gilmer, Lauren \& M. Garabrant, Jennifer \& H. Henry, Nancy. (2018). Predictors of burnout in public library employees. Journal of Librarianship and Information Science. 096100061875941. 


\begin{abstract}
Work stress and professional burnout are recognized as concerns for public library employees, yet little research has been conducted. The purpose of the current study was to better understand burnout and the contributing factors in a state-wide sample of public library employees in Indiana. Using a web-based survey, 171 employees of public libraries reported their level of burnout (emotional exhaustion, cynicism, and professional efficacy; Maslach Burnout InventoryGeneral Survey) and potential predictors, including levels of autonomy, co-worker support, work pressure, technology attitudes, and recovery experiences. A subset of 70 completed the burnout measures twice, allowing for predictions of change over time. Most predictors were correlated with burnout cross-sectionally, except for technology attitudes. Emotional exhaustion was positively associated with work pressure, and negatively associated with autonomy, role clarity, coworker support, and recovery experiences of relaxation, mastery, and control. Similar patterns were found for cynicism and reduced efficacy. However, over a period of approximately six months, only role clarity predicted decreased burnout (emotional exhaustion) above prior levels of burnout.
\end{abstract}




\section{Introduction}

Professional burnout - feeling emotionally exhausted or drained, possessing cynical attitudes, and having a reduced sense of professional efficacy or accomplishment - has long been identified as a particular troublesome consequence of human service work (Maslach \& Jackson, 1981). Yet, despite early attention to issues of professional burnout in public libraries (e.g., Birch, 1986; Haack, Jones, \& Roose, 1984), few studies have empirically examined predictors of burnout in these settings. Indeed, a recent review called for more research to better understand and address sources of stress in public libraries (Jordan, 2014). The purpose of the current study was to better understand burnout as a particular outcome of work stress in employees working in public libraries.

Models of burnout suggest that burnout can develop over time, in response to ongoing stressors at work. More specifically, the Job Demands-Resources model posits that burnout develops when job demands outpace resources (Bakker \& Demerouti, 2007; Bakker, Demerouti, De Boer, \& Schaufeli, 2003; Hakanen, Schaufeli, \& Ahola, 2008). Job demands require effort over time, resulting in costs to the individual (e.g., emotional exhaustion), while resources may reduce the costs of these demands, increase achievement of work goals, and further professional development. For example, longitudinal studies have shown that increases in demands (e.g., work overload and role conflict) and reductions in job-related resources (e.g., autonomy and coworker support) can predict increases in burnout (Schaufeli, Bakker, \& Van Rhenen, 2009). Literature also shows that job demands are positively related to a need for recovery (Jansen, Kant, van Amelsvoort, Nijhuis, \& van den Brandt, 2003; Sluiter, Frings-Dresen, van der Beek, \& Meijman, 2001; Sonnentag \& Zijlstra, 2006). Therefore, in addition to work-related aspects of job stress, experiences outside of work may also be important factors in reducing burnout. For 
example, Sonnentag and Fritz (2015) suggest that detaching from work and participating in other recovery experiences outside of work can be useful means of increasing employee well-being. Several authors describe the stressful nature of working in public libraries. For example, Jordan (2014) review focused on reduced library budgets coupled with increased patron needs (e.g., homeless populations) and rapidly changing technology demands. Christian (2015) highlighted similar issues, noting the public expectation that librarians embody the image of a "multitasking, boundless expert," who is "branded by not only information access and management, but also speed, accuracy, and knowledge presentation. (p.3)" Similarly, McDevitt and Jones (2013) describe the shift from stereotypes of working in "tranquil” library environments to the overwhelming nature of the current technology-driven environment. Together these point to several potential sources of burnout within the library work environment, particularly technology demands, high work pressure, and addressing social service needs of patrons. However, empirical studies of burnout in public library samples remain rare.

In an early study of public librarians using a previous version of the Maslach Burnout Inventory, Birch (1986) found that role ambiguity and role conflict (which were highly related to each other) were positively related to each subscale of burnout (Maslach \& Jackson, 1981). Affleck (1996) found similar correlations among bibliographic instruction librarians in public libraries. Other correlational studies have been conducted among academic librarians; for instance, in a study of Greek academic librarians, burnout did not depend on age, number of years as a librarian, or participation in decision-making, but, rather, was associated with less secure job contracts (Togia, 2005). In addition, more direct contact with library patrons was associated with enhanced feelings of personal accomplishment. In a more comprehensive study of potential predictors and job-related outcomes, Shupe, Wambaugh, and Bramble (2015) found 
that in a sample of academic librarians, work ambiguity was positively related to stress, burnout, work withdrawal, and health conditions. Moreover, work ambiguity was negatively associated with both life and job satisfaction. Role overload was significantly positively related to stress and burnout, and negatively related to job satisfaction, but was not a significant predictor of health conditions, work withdrawal or life satisfaction.

Given the few studies of predictors of burnout among library employees, this empirical investigation of burnout contributes to understanding and potentially reducing burnout in public libraries. Based on the Job Demands-Resources model and the extant literature on the impact of the work environment on employee burnout, specifically in library settings, we hypothesized that work pressure as a job demand would be associated with increased burnout, and that job-related resources of autonomy, role clarity, and coworker support would be associated with reduced burnout. Technology could be a conceptualized both as a demand (e.g., requiring changing expertise) or as a resource (e.g., increasing efficiency of work). We hypothesized that the extent to which participants hold positive attitudes toward technology would be associated with reduced burnout. Finally, we also hypothesized that recovery from work stress would function as a potential resource, given that prior work has shown recovery experiences outside of work (like relaxation or mastering a new skill) are associated with lower levels of burnout (Sonnentag \& Fritz, 2007). However, these experiences have yet to be examined among library employees in the published professional literature.

\section{Methods}

\section{Study Objectives}

This study stemmed from a partnership between the Indiana State Library and university researchers to develop an approach to address staff burnout in library employees. As part of that 
work, we conducted a needs assessment survey, presented webinars about burnout, and conducted a second survey with expanded measures. The focus of the current paper is to better understand the phenomenon of burnout in public libraries. First, we examined correlates of burnout. Then, for a subsample of librarians who completed both surveys, we controlled for prior levels of burnout to assess predictors of change in burnout.

\section{Participants and Procedures}

The Indiana State Library maintains a listserv primarily consisting of staff from libraries in the state. Using the listserv, staff were invited to participate in two surveys (July-August 2016 and November-December 2016). The primary purpose of the first survey was to assess the extent of burnout and perceived training needs related to burnout. In the second survey, we included additional measures to examine correlates of burnout. Participants were not offered compensation for participation and were informed that each survey was voluntary and anonymous. The first survey required 10 minutes for participants to complete, and the second survey required approximately 20 minutes.

Three hundred sixty-six library staff completed the first survey, and 226 library staff completed the second survey. Because additional measures were added to the second survey, the current analysis focuses on those who completed the second survey in order to examine a comprehensive set of predictors. For the subset of participants who completed both surveys, we merged data based on a unique ID the participant provided (first two letters of mother's maiden name, the day of birth, and last three letters of birth city) that were collapsed to form a unique ID. Because responsibilities and work environments may differ among types of libraries (e.g., public, school, academic), we further restricted the sample to focus on public libraries, which 
resulted in 171 respondents; 70 completed both surveys and were able to be linked for longitudinal analyses.

\section{Measures}

Participants completed the surveys online through Qualtrics (Qualtrics, 2013).

Demographic information included age, gender, race, ethnicity, education, primary job role, length of time in position, length of time in library system, and supervisor status. We also assessed variables related to job demands such as size of population served, percentage of workweek spent interacting with the public, average hours worked per week, and frequency of providing social services. We included an open-ended question to assess what participants value in their work to better understand the context of work in public libraries.

\section{Burnout}

Burnout was assessed with the Maslach Burnout Inventory-General Survey (MBI-GS), a 16-item burnout measure with strong internal validity and construct validity used to assess burnout among people who are not necessarily providing human services (Langballe, Falkum, Innstrand, \& Aasland, 2006; Maslach, Jackson, \& Leiter, 2006). This is a widely used inventory assessing three essential components of burnout: emotional exhaustion (e.g., "I feel emotionally drained from my work”), cynicism (e.g., "I've become less interested in my work since I started this job”), and professional efficacy (e.g., “At my work, I feel confident that I am effective at getting things done”). Means were calculated for each of the subscales to represent overall measure of emotional exhaustion, cynicism, and professional efficacy, ranging from 0 (never) to 6 (every day). This measure has demonstrated good convergent validity and internal consistency 
(Langballe et al., 2006). In the current sample, the subscales had acceptable internal consistency (emotional exhaustion $\alpha=92$; cynicism $\alpha=$.73; personal efficacy $\alpha=$.73).

\section{Autonomy}

The degree of autonomy felt at work was assessed using a 10-item Factual Autonomy Scale (Spector \& Fox, 2003). The first seven items represent how often the worker needs permission to stop working (e.g., "In your present job, how often do you have to ask permission to take a rest break?”). Responses were on a 5-point scale from “Never” (1) to “Always” (5). The final three items consist of how often events occur at a job that threaten autonomy (e.g. “How often does someone tell you what you are to do?”). Responses were on a 5-point scale ranging from "Never" (1) to "Every day" (5). We averaged the 10 items into one total score to measure autonomy. This scale has been shown to have good convergent validity and discriminant validity (Spector \& Fox, 2003). The current scale had good internal consistency $(\alpha=.88)$.

Role Clarity

Role clarity was assessed using the Role Clarity Index (Donnelly \& Ivancevich, 1975). This scale measures the extent that workers understand job expectations (e.g.,"Do you feel you are always as clear as you would like to be about what you have to do on your job?”).

Responses were on a 5-point scale from "not at all clear" (1) to "perfectly clear" (5).This scale has been shown to have adequate split-half internal consistency $(\alpha=.76)$. For the current study, we found the scale to have good internal consistency $(\alpha=.91)$.

Coworker support

Coworker support was assessed using the 10-item scale to assess emotional and instrumental support from co-workers (Ducharme \& Martin, 2000). Items include “My 
coworkers are friendly towards me," and "My coworkers assist me with unusual work

problems.” The current scale had good internal consistency ( $\alpha=.95)$.

Work Pressure

Pressure at work was assessed using the Quantitative Workload Inventory (Spector \& Jex, 1998). Each item assesses perceptions of the amount and time pressure of employee workload. For example, "How often does your job require you to work very fast?" and "How often is there a great deal to be done?" The current scale had good internal consistency ( $\alpha=.83)$. Attitudes about technology

We assessed attitudes toward technology using nine items created for this study. Items were created based on the concepts from the Attitudes Toward Information Technology Scale (Gokhale, Brauchle, \& Machina, 2013). We included six positive attitude items (e.g.,"IT is useful for my job”) and three negative attitude items (e.g.,"IT interferes with my productivity”). Responses ranged from 1 (Strongly disagree) to 5 (Strongly agree). Negative items were reversescored so higher values indicated more positive attitudes toward technology. This scale had adequate internal consistency $(\alpha=.70)$.

Recovery Experiences

Recovery experiences from work were assessed with the Recovery Experience Questionnaire (Sonnentag \& Fritz, 2007). This measure captures how people recover from work stress in four categories: Psychological detachment (e.g.,"I forget about work”), Relaxation (e.g.,"I use the time to relax"), Mastery (e.g.,"I do things that broaden my horizons”), and Control (e.g." "I decide my own schedule”). Responses ranged from 1 (Strongly disagree) to 5 (Strongly agree). This measure demonstrates good convergent validity and internal consistency 
((Sonnentag \& Fritz, 2007)). In the current sample, the subscales had high internal consistency

(psychological detachment $\alpha=81$; relaxation $\alpha=.94$; mastery $\alpha=.85$; Control $\alpha=.88$ ).

What participants value

At the end of the survey, we asked what participants value in their work using one short answer, open-ended question: "What do you value most about the work you do?"

\section{Data Analysis}

First, using only the responses from the second survey $(\mathrm{N}=171)$, we created a correlation matrix to examine which variables correlated with burnout cross-sectionally (see Tables 1 and 2). We then entered variables that were correlated with emotional exhaustion, cynicism, or professional efficacy $(p<.10)$ into three separate multiple regression analyses predicting each burnout subscale (e.g., items correlated with emotional exhaustion were entered in the model to predict emotional exhaustion). Finally, we examined whether predictors of emotional exhaustion, cynicism, and professional efficacy were associated with change in burnout. We conducted three separate hierarchical multiple regressions to test our multiple regression models for each burnout measure (Step 2), while controlling for prior burnout (Step 1). For the qualitative data, we categorized responses using emergent content analysis (Hsieh \& Shannon, 2005). Two coders independently read responses and created categories that best fit the data. After agreeing on the categories, the two coders read and categorized each response, compared ratings and came to consensus. A third team member reviewed the coding.

Results

\section{Correlations}

Emotional exhaustion was significantly correlated with younger age $(r=-.19, \mathrm{p}<.05)$, and at a trend level with being female (see Table 1). Similarly, cynicism was negatively correlated at 
a trend level $(\mathrm{p}<.10)$ with age $(\mathrm{r}=-.15)$, and with being female $(\mathrm{r}=.13)$. Professional efficacy was significantly correlated with increased age $(\mathrm{r}=.23, \mathrm{p}<.01)$ and at a trend level with years in position ( $\mathrm{r}=.19, \mathrm{p}<.10$ ) (see Table 1). These background characteristics were controlled for in later analyses.

Correlates between burnout, work demands and resources, and recovery experiences are shown in Table 2. As hypothesized, emotional exhaustion was significantly correlated with increased work pressure $(\mathrm{r}=.27, \mathrm{p}<.01)$, and decreased autonomy $(\mathrm{r}=-.35, \mathrm{p}<.01)$, role clarity $(\mathrm{r}=-$ $.44, \mathrm{p}<.01)$, and coworker support $(\mathrm{r}=-.38, \mathrm{p}<.01)$. Emotional exhaustion was negatively correlated with three of the four subscales of recovery experiences: relaxation $(r=-.36, p<.01)$, mastery ( $\mathrm{r}=-.37, \mathrm{p}<.01)$, and control $(\mathrm{r}=-.30, \mathrm{p}<.01)$. Only two variables were not significantly related: attitudes about technology and detachment as a recovery strategy.

Cynicism showed a similar pattern, correlated with decreased autonomy $(r=-.28, p<.01)$, role clarity $(\mathrm{r}=-.43, \mathrm{p}<.01)$, and coworker support $(\mathrm{r}=-.32, \mathrm{p}<.01)$ (see Table 2$)$. Cynicism was also negatively correlated with the same three recovery experiences outside of work: relaxation $(\mathrm{r}=-.31, \mathrm{p}<.01)$, mastery $(\mathrm{r}=-.35, \mathrm{p}<.01)$, and control $(\mathrm{r}=-.32, \mathrm{p}<.01)$. However, work pressure only reached a trend-level $(\mathrm{r}=.14, \mathrm{p}<.10)$.

Professional efficacy had fewer job-related correlates, and was significantly associated with increased role clarity $(\mathrm{r}=.37, \mathrm{p}<.01)$, but not with work pressure and only trend levels with autonomy $(\mathrm{r}=.14, \mathrm{p}<.10)$ and co-worker support $(\mathrm{r}=.14, \mathrm{p}<.10)$. Professional efficacy was positively correlated with frequency of recovery experiences outside of work: relaxation $(\mathrm{r}=.22$, $\mathrm{p}<.01)$, mastery $(\mathrm{r}=.26, \mathrm{p}<.01)$, and control $(\mathrm{r}=.25, \mathrm{p}<.01)$, but not detachment (see Table 2$)$.

\section{Multiple regressions}


A multiple linear regression was used to predict emotional exhaustion based on the variables that were found to correlate with emotional exhaustion ( $\mathrm{p}<.10)$ (i.e., age, female status, autonomy, role clarity, work pressure, coworker support, psychological detachment, relaxation, mastery, and control). As shown in Table 3, the overall model was significant ( $F$ (10, $139)=10.19, \mathrm{p}<.001)$ and able to account for $42.3 \%$ of the variance in emotional exhaustion. Increased emotional exhaustion was predicted by increased work pressure $(\beta=.14, \mathrm{p}<.05)$ and by decreased autonomy at work $(\beta=-.24, \mathrm{p}<.01)$, role clarity $(\beta=-.17, \mathrm{p}<.05)$, coworker support $(\beta=-$ $.20, \mathrm{p}<.01)$, strategies of relaxation $(\beta=-.18, \mathrm{p}<.05)$, and mastery $(\beta=-.23, \mathrm{p}<.01)$.

The model predicting cynicism was also statistically significant and predictors accounted for $32.5 \%$ of the variance, $F(9,140)=7.48, \mathrm{p}<.001$. However, individually, only 3 variables were significant predictors: decreased autonomy $(\beta=-.17, \mathrm{p}<.05)$, role clarity $(\beta=-.21, \mathrm{p}<.05)$, and lower mastery as a recovery strategy $(\beta=-.23, \mathrm{p}<.01)$. Similarly, the multiple linear regression predicting professional efficacy was statistically significant and predictors accounted for $22.0 \%$ of the variance, $F(9,141)=4.42, \mathrm{p}<.001$. However, after accounting for all other correlated variables, increased role clarity $(\beta=.26, \mathrm{p}<.01)$ was the only significant predictor.

Hierarchical regression predicting change in burnout

For the subsample of participants with two surveys linked over time, hierarchical multiple regressions assessed the ability of the above models to predict burnout, controlling for the initial level of burnout - essentially predicting change over time. For emotional exhaustion, the initial level explained $48.9 \%$ of the variance in emotional exhaustion at the second survey $(\beta=.71, \mathrm{p}<.00)$. In Step two, the predictor variables accounted for an additional $14.8 \%$ of the variance in emotional exhaustion $\left(\Delta R^{2}=.148, \Delta F(9,53)=2.21, \mathrm{p}<.05\right)$. In the final model, role clarity $(\beta=-.23, \mathrm{p}<.05)$ was a statistically significant predictor of emotional exhaustion in 
addition to prior emotional exhaustion $(\beta=.54, \mathrm{p}<.01)$. That is, accounting for other predictors, role clarity was the only significant predictor of reduced emotional exhaustion over time other than prior emotional exhaustion in the new model. For cynicism, prior cynicism significantly predicted current cynicism $(\beta=.85, \mathrm{p}<.01)$. In step two, the other variables did not account for a significant increase in variance explained, $\Delta R^{2}=.039, \Delta F(9,54)=0.95, \mathrm{p}=.491$. Similarly, prior professional efficacy significantly predicted current professional efficacy $(\beta=.85, \mathrm{p}<.01)$; however, additional variables did not increase the variance accounted for by initial levels of professional efficacy $\left(\Delta R^{2}=.103, \Delta F(9,54)=1.41, \mathrm{p}=.206\right)$.

\section{What participants value most}

When we asked what participants value most in their work, 150 responded. The top three themes involved relationships with patrons $(n=77)$, with community $(n=34)$, and with colleagues $(n=29)$. Participants valued being able to help patrons with specific resources (e.g., "Being able to connect patrons to what they need, whether that be resources, programs, or early literacy training (through story times),”) as well as getting to know the patrons (e.g., "Developing relationships with families who come to the library.”). Some described the positive impact on patrons as well, "Empowering people with information to make positive life choices," and enjoying the appreciation of patrons when participants do make a difference, e.g., "When people hug me after I help them do a simple computer task, it makes me feel on top of the world.” Beyond the specific patrons, participants also described the impact of serving the broader community as well (e.g. "Giving back to the entire community and making the library a place for everyone in the community," "Becoming a better partner to the community and creating new partnerships.”). Participants also valued working with and helping other staff (e.g., "I work with extremely talented, caring and dedicated people who work well together both intra- 
and inter-departmentally,” "Helping other staff succeed by training them.”) and appreciated supervisors who create a positive environment (e.g., "I work in a supportive, encouraging, “yes” environment.”) as well as opportunities for growth (e.g., "I value and enjoy the fact that since I got a new supervisor 15 months ago, I have been given more responsibility”).

\section{Discussion}

Few studies have assessed predictors of burnout in public library staff. Thus, this study contributes an empirical investigation of potential sources of work-related distress, highlighting several job and recovery-related factors to be associated with increased emotional exhaustion and cynicism and decreased professional efficacy. Important job-related variables appear to be work pressure (associated with greater emotional exhaustion) and protective factors of autonomy, role clarity, and coworker support (for emotional exhaustion and to a lesser extent cynicism). These are similar to correlates in other human service fields (Green, Albanese, Shapiro, \& Aarons, 2014; Halbesleben, 2006; Uzondu, 2017).

Of these job-related predictors, role clarity emerged as being related to each of the three components of burnout, and was the only clear predictor of change in burnout in the smaller subsample. This finding maps onto the earliest studies of public librarian showing that role ambiguity was particularly problematic, associated with increased burnout (Birch, 1986). Having clear expectations might also help overcome sources of stress related to the changing roles for librarians in providing social services to patrons while fulfilling demanding technology expectations (Christian, 2015; Jordan, 2014). One practical implication for managers in public libraries is to ensure that role responsibilities are clearly defined, for example, in creating specific job descriptions, providing ongoing supervision of employees, and educating patrons about what to expect from library employees. 
Recovery experiences were also important correlates of burnout. Although 3 of the four types of recovery experiences were correlated with each of the components of burnout, the regression analyses accounting for other variables suggest that mastery experiences outside of work (e.g., "I do things that challenge me”) may be particularly important for lower emotional exhaustion and cynicism. In addition, relaxation strategies (e.g., "I do relaxing things") were associated with reduced emotional exhaustion, but not cynicism or professional efficacy. Because human services employees may be required to perform a greater amount of emotional labor in their work than non-human services employees (Morris \& Feldman, 1996), recovery experiences that include pursuing non-work goals (mastery) or relaxing activities (low effort) may be particularly important for renewing depleted emotional resources. This notion is in line with previous research on flight attendants (Sonnentag \& Natter, 2004) and teachers (Sonnentag, 2001) whose participation in non-work leisure time activities was positively associated with well-being. Our findings suggest that it may be helpful to encourage outside interests where library staff can develop skills and a sense of achievement, which in turn may increase energy and meaning. In addition, relaxation strategies may be helpful for addressing emotional exhaustion. For example, studies of mindfulness and similar relaxation strategies in other professions have been helpful in reducing burnout (Krasner et al., 2009; Salyers et al., 2011). Although not directly addressing burnout, Ciolacu (2015) conducted an intervention for librarians to help improve emotional regulation and found improvements in emotional effort reported at work. Emotional regulation skills may be similarly beneficial in helping reduce emotional exhaustion in library settings.

Notably, technology attitudes did not predict burnout. This was a surprise, particularly given prior literature emphasizing the stressful demands of rapidly changing technology (Jordan, 2014; 
McDevitt \& Jones, 2013) and public expectations that library staff are technology experts (Christian, 2015). One problem may have been how we measured the role of technology. We created a scale specifically for this study; however, the items had low internal consistency, suggesting they may not have measured a unitary construct. It also may be that we were not asking the right questions about technology. For example, items referring to "information technology” may have been too vague. In addition, open-ended responses about what staff valued suggested that technology may be a positive aspect of the work, rewarding as a challenge in itself (e.g. "staying current" with technology) and as a tool to help patrons and to feel more effective in their role. Given that some respondents valued the role of being a technology expert, perhaps the lack of efficient, fast, or adequate technological resources could be linked to burnout; however, we did not assess those issues. The role of technology may also differ in types of settings; for example, technology may be more critical in academic libraries, which may have more diverse technological demands than public libraries where a smaller group of specialists carry the majority of responsibility related to new technologies.

There are several limitations to this study. The majority of analyses were cross-sectional, and we did not have the same assessments at both time points to assess a larger number of predictors over time. When we could measure change, however, we were limited by small sample size, with power to detect only large effects. Finally, there are a number of other factors that might influence burnout that were not assessed in this study; for example, with reduced funding, worries of job security may be an additional work-related demand (Demerouti, Bakker, de Jonge, Janssen, \& Schaufeli, 2001).

This study adds to the burnout literature by focusing on understanding potential sources of burnout for an understudied population (public librarians). Another strength was the large 
number of participants (for cross sectional analyses) who were from different public libraries across a state, which enhances generalizability. Future studies could examine a larger sample with repeated measures to more effectively model relationships over time. In addition, a better understanding of how recovery experiences outside of work can help buffer work stress, specifically for employees within the human services sector, is needed. For example, it may be helpful to examine specific recovery activities that are negatively related to burnout.

Additionally, future research could explore contextual variables within high emotional demand work environments that allow for employee recovery experiences. 


\section{References}

Affleck, M. A. (1996). Burnout among bibliographic instruction librarians. Library \& Information Science Research, 18(2), 165-183. doi:https://doi.org/10.1016/S0740-8188(96)90018-3

Bakker, A. B., \& Demerouti, E. (2007). The job demands-resources model: State of the art. Journal of Managerial Psychology, 22(3), 309-328.

Bakker, A. B., Demerouti, E., De Boer, E., \& Schaufeli, W. B. (2003). Job demands and job resources as predictors of absence duration and frequency. Journal of Vocational Behavior, 62(2), 341-356.

Birch, N. (1986). Perceived Role Conflict, Role Ambiguity, and Reference Librarian Burnout in Public Libraries. Library and Information Science Research, 8(1), 53-65.

Christian. (2015). A passion deficit: Occupational burnout and the new librarian A recommendation report. Southeastern Librarian, 62(4), 2-11.

Ciolacu, M. V. (2015). Emotional regulation strategies proposed to librarians to reduce emotional burnout. Romanian Journal of Experimental Applied Psychology, 6(2).

Demerouti, E., Bakker, A. B., de Jonge, J., Janssen, P. P., \& Schaufeli, W. B. (2001). Burnout and engagement at work as a function of demands and control. Scand J Work Environ Health, 27(4), 279-286.

Donnelly, J. H., \& Ivancevich, J. M. (1975). Role clarity and the salesman. The Journal of Marketing, 7174.

Ducharme, L. J., \& Martin, J. K. (2000). Unrewarding work, coworker support, and job satisfaction: A test of the buffering hypothesis. Work and Occupations, 27, 223+.

Gokhale, A. A., Brauchle, P. E., \& Machina, K. F. (2013). Scale to measure attitudes toward information technology. International Journal of Information and Communication Technology Education (IJICTE), 9(3), 13-26.

Green, A. E., Albanese, B. J., Shapiro, N. M., \& Aarons, G. A. (2014). The roles of individual and organizational factors in burnout among community-based mental health service providers. Psychological Services, 11(1), 41. 
Haack, M., Jones, J. W., \& Roose, T. (1984). Occupational burnout among librarians. Drexel Library Quarterly, 20(2), 46-72.

Hakanen, J. J., Schaufeli, W. B., \& Ahola, K. (2008). The Job Demands-Resources model: A three-year cross-lagged study of burnout, depression, commitment, and work engagement. Work \& Stress, 22(3), 224-241.

Halbesleben, J. R. (2006). Sources of social support and burnout: a meta-analytic test of the conservation of resources model. Journal of Applied Psychology, 91(5), 1134.

Hsieh, H.-F., \& Shannon, S. E. (2005). Three approaches to qualitative content analysis. Qualitative Health Research, 15(9), 1277-1288.

Jansen, N., Kant, I., van Amelsvoort, L., Nijhuis, F., \& van den Brandt, P. (2003). Need for recovery from work: evaluating short-term effects of working hours, patterns and schedules. Ergonomics, 46(7), 664-680.

Jordan, M. W. (2014). All stressed out, but does anyone notice? Stressors affecting public libraries. Journal of Library Administration, 54(4), 291-307. doi:10.1080/01930826.2014.924318

Krasner, M. S., Epstein, R. M., Beckman, H., Suchman, A. L., Chapman, B., Mooney, C. J., \& Quill, T. E. (2009). Association of an Educational Program in Mindful Communication With Burnout, Empathy, and Attitudes Among Primary Care Physicians. JAMA: Journal of the American Medical Association, 302(12), 1284-1293.

Langballe, E. M., Falkum, E., Innstrand, S. T., \& Aasland, O. G. (2006). The factorial validity of the Maslach Burnout Inventory-General Survey in representative samples of eight different occupational groups. Journal of Career Assessment, 14(3), 370-384.

Maslach, C., \& Jackson, S. E. (1981). The measurement of experienced burnout. Journal of Organizational Behavior, 2(2), 99-113.

Maslach, C., Jackson, S. E., \& Leiter, M. P. (2006). Maslach burnout inventory: CPP.

McDevitt, T., \& Jones, J. (2013). We are all in this together: Stress reduction and team building activities for modern library organizations. Codex (2150-086X), 2(3), 78-99. 
Morris, J. A., \& Feldman, D. C. (1996). The dimensions, antecedents, and consequences of emotional labor. Academy of Management Review, 21(4), 986-1010. doi:10.5465/AMR.1996.9704071861

Qualtrics, I. (2013). Qualtrics. com: Qualtric Research Suite Provo, UT.

Salyers, M. P., Hudson, C., Morse, G., Rollins, A. L., Monroe-DeVita, M., Wilson, C., \& Freeland, L. (2011). BREATHE: A pilot study of a one-day retreat to reduce burnout among mental health professionals. Psychiatric Services, 62(2), 214-217.

Schaufeli, W. B., Bakker, A. B., \& Van Rhenen, W. (2009). How changes in job demands and resources predict burnout, work engagement, and sickness absenteeism. Journal of Organizational Behavior, 30(7), 893-917.

Shupe, E. I., Wambaugh, S. K., \& Bramble, R. J. (2015). Role-related stress experienced by academic librarians. The Journal of Academic Librarianship, 41(3), 264-269.

Sluiter, J. K., Frings-Dresen, M. H., van der Beek, A. J., \& Meijman, T. F. (2001). The relation between work-induced neuroendocrine reactivity and recovery, subjective need for recovery, and health status. Journal of Psychosomatic Research, 50(1), 29-37.

Sonnentag, S. (2001). Work, recovery activities, and individual well-being: a diary study. Journal of Occupational Health Psychology, 6(3), 196.

Sonnentag, S., \& Fritz, C. (2007). The Recovery Experience Questionnaire: development and validation of a measure for assessing recuperation and unwinding from work. Journal of Occupational Health Psychology, 12(3), 204.

Sonnentag, S., \& Fritz, C. (2015). Recovery from job stress: The stressor-detachment model as an integrative framework. Journal of Organizational Behavior, 36(S1).

Sonnentag, S., \& Natter, E. (2004). Flight attendants' daily recovery from work: Is there no place like home? International Journal of Stress Management, 11(4), 366.

Sonnentag, S., \& Zijlstra, F. R. (2006). Job characteristics and off-job activities as predictors of need for recovery, well-being, and fatigue. Journal of Applied Psychology, 91(2), 330. 
Spector, P. E., \& Fox, S. (2003). Reducing subjectivity in the assessment of the job environment: Development of the Factual Autonomy Scale (FAS). Journal of Organizational Behavior, 24(4), 417-432.

Spector, P. E., \& Jex, S. M. (1998). Development of four self-report measures of job stressors and strain: Interpersonal Conflict at Work Scale, Organizational Constraints Scale, Quantitative Workload Inventory, and Physical Symptoms Inventory: Educational Publishing Foundation.

Togia, A. (2005). Measurement of burnout and the influence of background characteristics in Greek academic librarians. Library Management, 26(3), 130-138.

Uzondu, C. N. (2017). Influence of shift work and job autonomy on burnout among nurses International Journal of Communication, 12(1). 